This item was submitted to Loughborough's Research Repository by the author.

Items in Figshare are protected by copyright, with all rights reserved, unless otherwise indicated.

\title{
Annular diffusers with large downstream blockage effects for gas turbine combustion applications
}

\section{PLEASE CITE THE PUBLISHED VERSION}

http://dx.doi.org/10.2514/1.B34167

\section{PUBLISHER}

(C2011 by the authors. Published by the American Institute of Aeronautics and Astronautics

\section{VERSION}

VoR (Version of Record)

\section{PUBLISHER STATEMENT}

This work is made available according to the conditions of the Creative Commons Attribution-NonCommercialNoDerivatives 4.0 International (CC BY-NC-ND 4.0) licence. Full details of this licence are available at: https://creativecommons.org/licenses/by-nc-nd/4.0/

\section{LICENCE}

CC BY-NC-ND 4.0

\section{REPOSITORY RECORD}

Walker, Alastair Duncan, Jonathan F. Carrotte, and Paul A. Denman. 2015. "Annular Diffusers with Large Downstream Blockage Effects for Gas Turbine Combustion Applications”. figshare. https://hdl.handle.net/2134/19066. 


\title{
Annular Diffusers with Large Downstream Blockage Effects for Gas Turbine Combustion Applications
}

\author{
A. Duncan Walker,,- Jonathon F. Carrotte, \pm and Paul A. Denman $\$$ \\ Loughborough University, Loughborough, England LE11 3TU, United Kingdom
}

DOI: $10.2514 / 1 . B 34167$

\begin{abstract}
In engineering applications, diffuser performance is significantly affected by its boundary conditions. In a gas turbine combustion system, the space envelope is limited, the inlet conditions are generated by upstream turbomachinery, and the downstream geometry is complex and in close proximity. Published work discusses the impact of compressor-generated inlet conditions, but little work has been undertaken on designing diffusers to accommodate a complex downstream geometry. This paper considers the design of an annular diffuser in the presence of a large downstream blockage. This is most applicable in the combustion system of a low-emission landbased aero-derivative gas turbine, where immediately downstream of the diffuser approximately $85 \%$ of the flow moves outboard and $15 \%$ moves inboard to supply the various flame-tube and turbine-cooling features. Several diffuser concepts are numerically developed and demonstrate 1) the interaction between the diffuser and downstream geometry and 2) how this varies with changes in diffuser geometry. A preferred concept is experimentally evaluated on a low-speed facility that simulates the combustion system and provides compressorgenerated inlet conditions. A conventionally designed aero-derivative diffuser system is also evaluated and, with reference to this datum, the system total pressure losses are reduced by between 20 and $35 \%$.
\end{abstract}

\section{Nomenclature}

$\begin{array}{ll}A & =\text { passage area } \\ \mathrm{AR} & =\text { area ratio } \\ B & =\text { diffuser exit } \\ C & =\text { inner annulus } \\ C p & =\text { static pressure rise coefficient } \\ D & =\text { combustor exit } \\ D, d & =\text { diameter } \\ h & =\text { annulus passage height } \\ L & =\text { length } \\ \dot{m} & =\text { mass flow rate } \\ N & =\text { rotor speed } \\ P, p & =\text { local total or static pressure } \\ R, r & =\text { radius } \\ T, t & =\text { local total or static temperature } \\ T o_{1} & =\text { total temperature in rig inlet } \\ U & =\text { velocity } \\ U_{\text {blade }} & =\text { rotor midpassage blade speed } \\ V a & =\text { midpassage axial velocity } \\ y+ & =\text { dimensionless wall distance } \\ \alpha & =\text { kinetic energy coefficient } \\ \beta & =\text { diffuser cant angle } \\ \Delta R & =\text { change in radius } \\ \lambda & =\text { total pressure loss coefficient } \\ \rho & =\text { density } \\ - & =\text { area-weighted spatially averaged mean value } \\ \sim & =\text { mass-weighted spatially averaged mean value }\end{array}$

Subscripts

$A \quad=$ outlet-guide-vane exit traverse plane

$B=$ diffuser exit traverse plane

Received 29 October 2010; revision received 18 March 2011; accepted for publication 12 April 2011. Copyright $@ 2011$ by the authors. Published by the American Institute of Aeronautics and Astronautics, Inc., with permission. Copies of this paper may be made for personal or internal use, on condition that the copier pay the $\$ 10.00$ per-copy fee to the Copyright Clearance Center, Inc., 222 Rosewood Drive, Danvers, MA 01923; include the code 0748-4658/ 11 and $\$ 10.00$ in correspondence with the CCC.

*Lecturer in Applied Aerodynamics; a.d.walker@lboro.ac.uk.

'Reader in Experimental Propulsion Aerodynamics, Department of Aeronautical and Automotive Engineering; j.f.carrotte@lboro.ac.uk.

Research Fellow, Department of Aeronautical and Automotive Engineering; p.a.denman@lboro.ac.uk.

$$
\begin{array}{ll}
C 1-3 & =\text { inner annulus traverse planes } \\
X 0 & =\text { rig inlet traverse plane } \\
X 1 & =\text { rotor inlet traverse plane } \\
Z & =\text { rotor exit traverse plane } \\
1,2 & =\text { arbitrary inlet, outlet stations }
\end{array}
$$

\section{Introduction}

D IFFUSERS are used in a wide variety of engineering applications for converting flow kinetic energy into a static pressure rise. Although a large number of publications exist on characterizing the performance of diffusers, the mechanisms that determine these characteristics are often affected by the engineering environment in which the diffuser has to operate. In the case of a gas turbine engine, for example, annular diffusers can be found within exhaust system volutes, the intermediate ducting connecting different turbomachinery spools and within the combustion system. Such applications are usually characterized by a limited space envelope, inlet conditions that have been generated by upstream turbomachinery, and a complex downstream geometry. Not surprisingly, these effects can have a considerable impact on the diffuser design and its performance.

Within a gas turbine engine the limited space envelope usually means that the diffuser is closely coupled to, and therefore interacts with, the components on either side of it. The importance of inlet conditions on diffuser performance is widely acknowledged, and within a gas turbine these are typically generated by turbomachinery located immediately upstream of the diffuser. Several authors, such

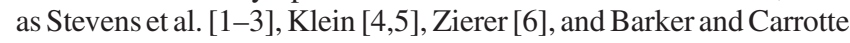
$[7,8]$, have considered this interaction between the compressor and the conditions it presents to the downstream diffuser. In particular, the annular diffuser can achieve a considerably higher area ratio and pressure recovery with the compressor-generated inlet conditions compared with those generated by a more classical ducted flow. This is due to the increased mixing and flow redistribution associated with the compressor-generated flowfields that pass into the diffuser. Using an integrated design approach Walker et al. [9] tailored the compressor exit conditions to promote secondary flows and thereby enable the downstream diffuser to achieve an even greater area ratio, well above conventional design limits. Additionally, some studies have also considered the potential effect of the diffuser exit conditions on its performance. Even for simple conical diffusers changes in performance are observed between a sudden expansion or when a downstream tail pipe is present [10]. However, for a gas turbine 
application the exit conditions are normally associated with a complex geometry such as an exhaust volute [11] or a combustion system (Figs. 1 and 2).

Within a gas turbine combustion system the annular diffuser reduces the kinetic energy of the flow issuing from the upstream compressor. This reduction in flow kinetic energy, before the flow distributing itself to the various flame tube features, is crucial for maintaining an acceptable pressure loss within the combustion system. For aero applications the diffuser exit condition is typically characterized by a sudden expansion of the flow into a dump cavity. In this region the flow either passes directly into the annular flame tube, via fuel injectors, or undergoes a free-surface expansion to enter the annuli surrounding the flame tube. Hence, although the flow through the combustion system is predominantly in the axial direction, a pressure field is generated to achieve the required flow distribution around the flame tube. Workers such as Fishenden and Stevens [12] and Bailey et al. [13] have shown how evidence of this pressure field can be observed at the diffuser exit, which helps to stabilize the diffuser flow and enable higher area ratios to be achieved. Further evidence of this downstream-upstream interaction is indicated by the more recent work of Walker et al. [14,15] relating to lean-burn combustion systems. This indicated the changing nature of this interaction due to the changing combustor porosity, in which a much higher portion of the flow passes directly through the fuel injectors and into the flame tube. Consequently, in this case, the diffuser can be subjected to both circumferential and radial variations of the pressure field by the downstream geometry.

This paper is concerned with the design of annular diffusers for applications where space is limited and, in particular, the potential for interaction with a complex downstream geometry is high. To demonstrate this, an annular diffuser for a land-based gas turbine combustion system is considered. As already discussed, for aerotype applications the flow through the combustion system is predominantly axial and the blockage downstream of the diffuser can be relatively modest. Nevertheless, and particularly in the case of lean-burn combustion, the effect of the blockage on diffuser

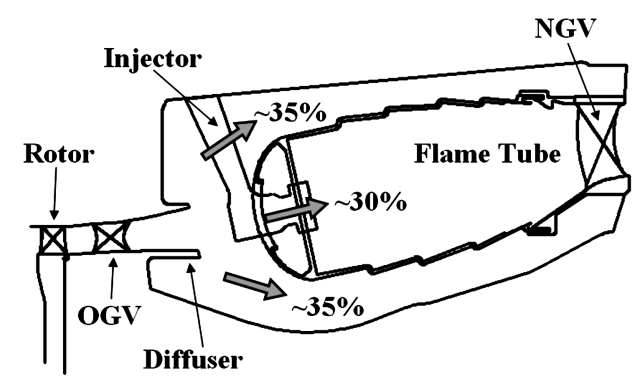

Fig. 1 Schematic of generic aero combustion system.

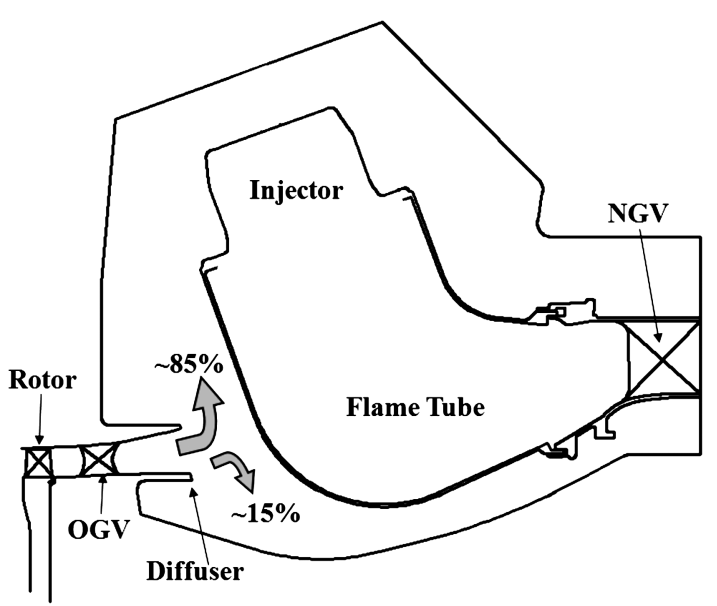

Fig. 2 Schematic of generic industrial combustions system. performance can be significant $[\underline{14}, \underline{15}]$. In contrast, for land-based gas turbines (either aero derivate or purpose-built) the much larger combustor volume dictates that the bulk of the flow moves radially outward downstream of the diffuser (Fig. 2). In addition, the amount of flow that moves outboard may also increase in the future with the employment of low-emission lean-burn technology. A diffuser must therefore be designed to accommodate very different exit conditions (notably, a high downstream blockage) relative to an aero system. In the current study various design concepts are initially investigated using numerical techniques, some of which are then evaluated on a low-speed experimental test facility.

\section{Numerical Methodology}

The increased numerical resource available to the designer has meant that computational fluid dynamics (CFD) is now invaluable to the design process. It is now possible, through the use of techniques such as large eddy simulation, to compute a time-accurate solution that is able to predict the onset of separation, which is a fundamentally unsteady phenomenon. However, such calculations are still computationally expensive and in order to perform several design iterations, within a practical time frame, time-averaged solutions of simplified, but representative geometries are currently the only viable option. To accomplish this here the commercial packages Gambit and FLUENT were used to generate the computational model and solve the Reynolds-averaged Navier-Stokes (RANS) equations. Although well-established standard RANS CFD techniques were employed it should be noted that care must be taken in the definition of the computational geometry, grid, boundary conditions, and turbulence model. The designer must have an appreciation of the flow physics present and the ability and/or limitations of the modeling techniques to capture this before a successful design can be confidently achieved.

The work presented used a higher-order Reynolds stress turbulence closure, as it is more suited to capturing the effects of curvature that are present in the current geometry. Simple eddyviscosity models are unable to capture these effects, due to their assumption of isotropic turbulence viscosity in the Boussinesq hypothesis for the Reynolds stresses. Versteeg and Malalasekera [16] report that, although achieving notable success, eddy-viscosity models can be inaccurate in unconfined flows such as far wakes and mixing layers, as the rate of production of turbulent kinetic energy can be much less than the rate of dissipation. Problems are also encountered for flows with large extra strains such as curved boundary layers, diverging passages, and swirling flows, where highly anisotropic turbulence has a dominant effect. Craft and Launder [17] reported that the $k-\varepsilon$ model will overpredict the total pressure losses in impingement regions whereas Bradshaw [18] reported that the model fails to predict the large total pressure losses caused by streamline curvature. Little et al. [19] predicted the flow in a dump diffuser combustion system and suggested that the latter failing leads to an underprediction of system total pressure loss for eddy-viscosity models, although this can be masked by the overprediction of impingement loss. Britchford et al. [20] demonstrated the superiority of the Reynolds stress model over a $k$ - $\varepsilon$ model in capturing the combined effects of strong pressure gradients and streamline curvature in an annular S-shaped duct. Similarly, Walker [21] also showed that a Reynolds stress model gave better agreement with measured data in a dump diffuser combustion system.

In addition to choosing the most applicable turbulence model it is also important to consider the treatment of the near-wall flow. One goal of the current work was to maximize the diffuser area ratio, but this relied on the ability of the CFD to predict the onset of flow separation. Essentially there are two choices; fully resolve the nearwall region or use a wall function to model it. The former is likely to yield better results, but the need for very fine mesh densities in the near-wall region makes this approach computationally impractical for large three-dimensional geometries. Using a standard wall function is more applicable to a rapid design process but poses some further issues. First, care must be taken when meshing the near-wall regions such that cell sizes result in $y+$ values for which the 
logarithmic law-of-the-wall is valid (i.e., greater than 30-60). Second, since the value of $y+$ is a function of the near-wall velocity it will tend to zero as the flow approaches separation. Hence, wall functions cannot accurately predict the point at which separation occurs. Further, the onset of separation is fundamentally an unsteady process that time-averaged RANS CFD will not capture. Nevertheless, RANS CFD and wall functions can be used to assess the proximity of separation when the flow prediction is examined with an experienced eye. For example, the imminent onset of separation can be revealed by the near-wall velocities, the shape of the radial velocity profile in the near-wall region and the wall shear stress values. Further, in the current work a datum configuration was computed containing a diffuser that experimental measurements had shown to be fully attached. Using this datum, subsequent configurations were easily classified as better, worse, closer to separation, etc.

Using the above numerical methodology, a variety of calculations were undertaken in which both the annular diffuser and a simplified downstream flame-tube system was included. In this way, the interaction between the downstream geometry and the flow within the annular diffuser was captured. However, modeling of the complete combustion system implies a significant computational overhead and so several models, of varying complexity, were used.

\section{A. Two-Dimensional Axisymmetric Model}

The geometry of this model (Fig. 3a) was intended for the rapid assessment of various preliminary diffuser concepts and therefore incorporated a number of simplifications. In terms of diffuser behavior it was assumed that the presence of the flame tube has a dominant effect. However, this effect is mainly influenced by the gross geometry of the flame tube and the associated flowfield distribution around it, rather than local features such as cooling rings, etc. Hence, in the simplified model the flame tube incorporated no

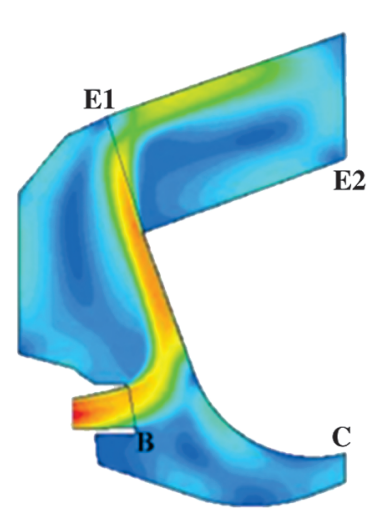

a) Simple 2-D

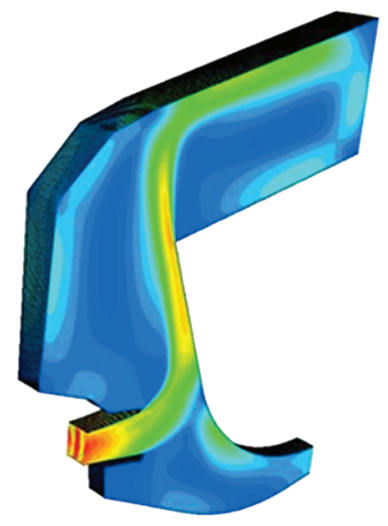

b) Simple 3-D

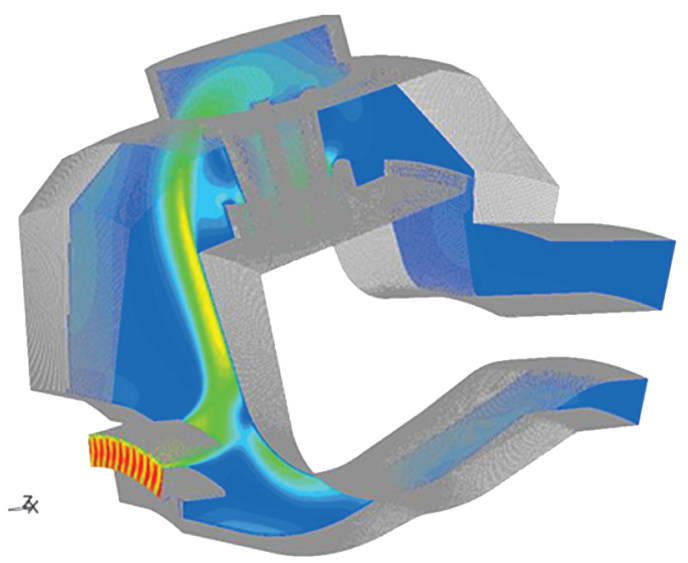

c) Featured 3-D

Fig. 3 Summary of numerical models (showing contours of total velocity). porosity and only two outlet conditions. The outlet close to the engine centerline passed approximately $15 \%$ of the inlet flow and is broadly representative of the cooling flow that is typically supplied to the inner nozzle guide vane (NGV) platform. On exiting the diffuser the remaining flow $(\sim 85 \%)$ must pass outboard, along the face of the flame tube, before either passing through the fuel injectors or providing coolant to the NGV outer platform. The summation of this flow passes through the outboard exit. This simplification was thought to maintain a reasonable approximation to the flow distribution in the vicinity of the diffuser exit. Both exit boundary conditions were specified using a zero gradient fixed mass flow condition. The inlet conditions were circumferentially averaged profiles based approximately on the conditions generated by the upstream compressor (see Sec. IV).

\section{B. Full 3-D Model}

Several geometries from the preliminary 2-D study were further investigated using a 3-D model (Fig. 3b). In this case, fully threedimensional inlet conditions were used that were broadly based on the conditions generated by the compressor within the experimental facility. Hence, these inlet conditions included compressor outletguide-vane (OGV) wakes and other compressor-generated flowfield features. In this way, the increased mixing and flow redistribution within the annular diffuser, due to the compressor-generated inlet conditions, was captured and therefore included in the design process. Calculations were performed over a sector that corresponded to two OGV passages and this enabled a detailed study of the diffuser flowfield. Alternatively the sector was also extended to include a complete sector of the flame tube that then enabled the flow through a fuel injector to be simulated (Fig. 3c). In this case, three outlet conditions were used to simulate the fuel injector flow $(\sim 70 \%)$ along with the NGV outboard $(\sim 15 \%)$ and inboard $(\sim 15 \%)$ coolant flows.

\section{Diffuser Designs}

The performance of a diffuser can be assessed in terms of the total pressure loss and static pressure rise between its inlet and outlet planes. However, it is the performance of the complete system that is of prime importance. Hence, this was mainly assessed in terms of the pressure loss coefficient between the inlet and the various outlet planes corresponding to the fuel injector or NGV coolant flows. These changes are presented in terms of the total pressure loss and static pressure rise coefficients derived from the calculated massweighted pressures between the various locations, i.e.,

$$
\lambda_{1-2}=\frac{\tilde{P}_{1}-\tilde{P}_{2}}{\tilde{P}_{1}-\tilde{p}_{1}} \quad C p_{1-2}=\frac{\tilde{p}_{2}-\tilde{p}_{1}}{\tilde{P}_{1}-\tilde{p}_{1}}
$$

where 1 and 2 are the upstream and downstream planes.

It should be noted that mass or momentum mix weighted values could have been used for performance assessment. Basically, the former method means the total loss associated with mixing out of the inlet profile (i.e., OGV wakes, etc.) is included in the combustion system performance, the latter removes the loss component generated if the inlet profile had mixed out at constant momentum. In this paper mass weighting was preferred for several reasons (e.g., the loss associated with the flow issuing from the diffuser is determined by its total kinetic energy, rather than its mixed-out value). However, the magnitude of the mixing loss associated with the inlet profile is small relative to the overall combustion system loss $(<5 \%)$. Hence, whichever weighting method is used makes little difference to the loss values and the overall conclusions. At a given location the amount of flow distortion (and hence potential and as-yet-unrealized loss) was assessed in terms of a kinetic energy flux coefficient. This indicates the amount of flow kinetic energy relative to that of a uniform profile, i.e.,

$$
\alpha=\frac{\int u^{3} \mathrm{~d} A}{\bar{U}^{3} A}
$$


It also follows that

$$
\tilde{P}=\tilde{p}+\alpha \frac{1}{2} \rho \bar{U}^{2}
$$

A further important design constraint is that the upstream turbomachinery, including the compressor OGV row, should not be affected by any changes to the annular diffuser. This objective is achieved if the static pressure distribution on the diffuser inlet plane, which is actually located at the OGV trailing edge, remains unchanged despite any changes in downstream geometry. Initially, this condition was relaxed for the preliminary design stages, but it was imposed as a requirement for the final designs.

\section{A. Datum Aero Diffuser}

For industrial gas turbines it can be attractive from a cost/ development viewpoint to modify an existing aero engine. In doing so these so-called aero derivatives maintain the original turbomachinery, including the prediffuser, changing only the downstream flame tube and combustor casings. Consequently, an initial aero datum diffuser was investigated that reflects the current design practice for an aero application where the flow through the combustion system is predominantly in the axial direction. The diffuser considered was been optimized for the equivalent aeroengine configuration. However, such a diffuser may not be optimal for the configuration being considered here, but it provides a good datum of practical relevance. For cost reasons it is attractive to retain the existing aero diffuser for the industrial land-based application. However, the impact of introducing a large downstream blockage on the annular diffuser was assessed along with the potential performance improvement of accommodating a new diffuser that was designed to account for a different downstream geometry.

The datum diffuser had a nondimensional length $L / h_{1}$ of approximately 2 , an area ratio of 1.5 , and incorporated $12^{\circ}$ outboard cant, which reflects the current design practice for this type of application. A contour plot of total velocity illustrates the generated flowfield, in which the flow, upon exiting the diffuser, impinges on the flame tube (Fig. 4a). This impingement process and the high-velocity gradients associated with the jet flow will produce turbulent energy and hence total pressure loss. The majority of the flow $(\sim 85 \%)$ then moves radially outward and forms a relatively high-velocity wall jet, whereas the remaining flow moves inboard. The strong jet along the front face of the flame tube and subsequent impingement on the outer casing is a high source of loss as can be seen from the nondimensionalized contours of total pressure (Fig. 4a). This will negatively impact the feed to the fuel injectors and make balancing the NGV cooling flows more challenging. Closer inspection of the velocity contours suggest that the outer wall of the datum diffuser constrains the flow from moving outboard, whereas the inner-wall flow has separated due to the pressure field generated by the downstream flame tube. This will affect the efficiency of the diffuser in reducing the kinetic energy of the flow.
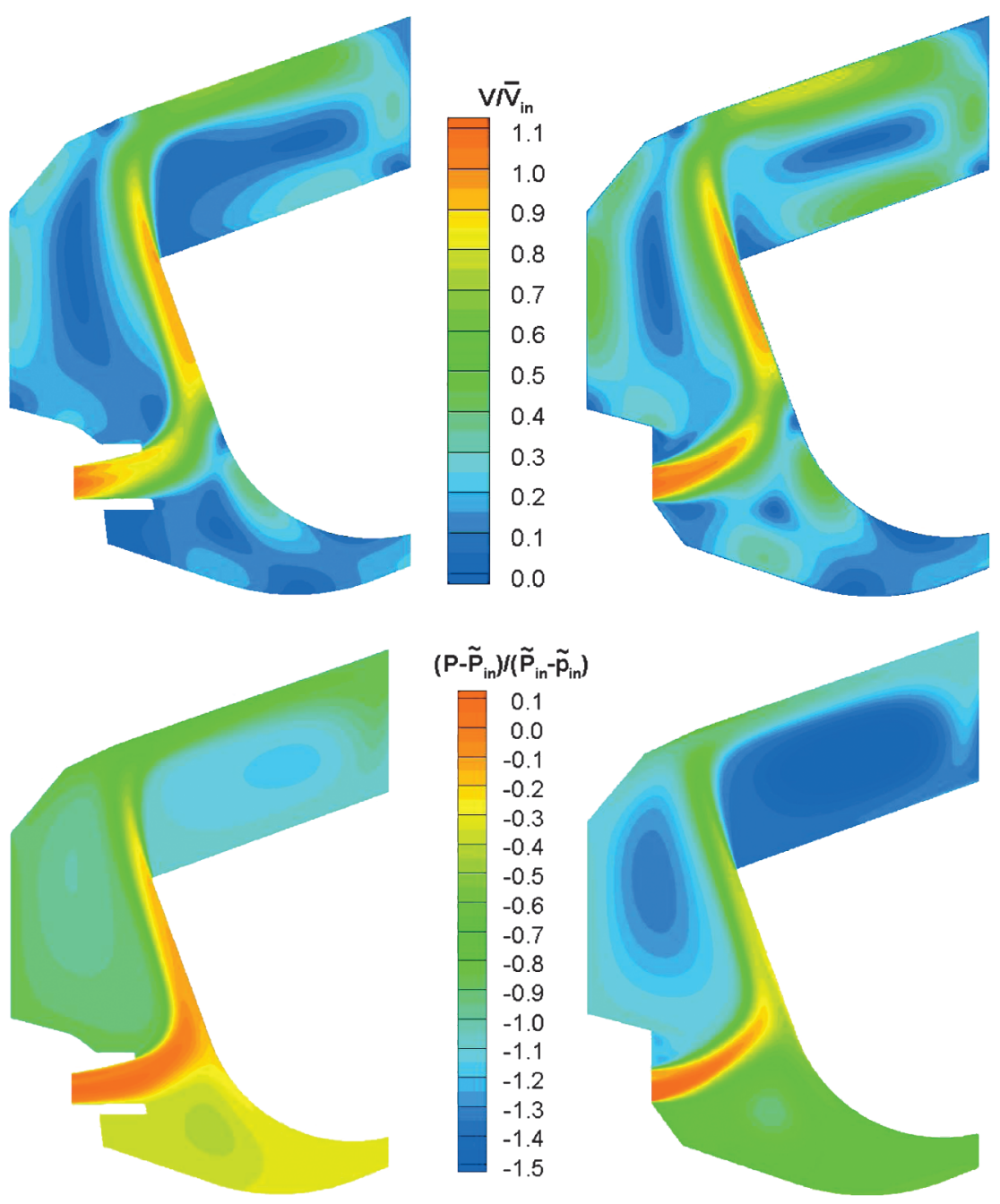

a) Datum diffuser

b) No diffuser

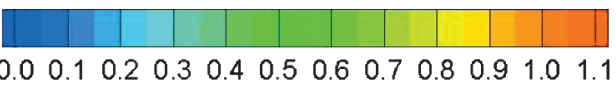

Fig. 4 Total velocity and total pressure contours. 
Removal of the annular diffuser entirely, although impractical, does reveal where the compressor efflux would flow if only influenced by the downstream combustor geometry (Fig. 4b). It is interesting to note that the curvature of the flow due to the presence of the flame tube can be observed relatively close to the compressor efflux plane. The data suggest that the effect of the flame-tube blockage with the diffuser present is likely to be present along approximately $80 \%$ of the diffuser length. On this basis, the downstream blockage presented to the diffuser is defined as large and reflects a strong interaction between the diffuser and downstream geometry. It also suggests that there is some conflict between the flow curvature and diffusion associated with the diffuser and downstream flame tube.

\section{B. Integrated Diffuser}

The impact of the pressure field generated by the large downstream blockage means that conventional diffuser design charts are of limited use. Hence, an alternative design strategy must be formulated; as a starting point, the flowfield generated with the diffuser removed was investigated. This defines the flowfield generated by the flame tube, the objective then being to design a diffuser that accommodates this flowfield. For example, streamlines can be identified that divide the main compressor efflux from the outer and inner recirculating regions. Aligning any surfaces with these streamlines would enable the basic flowfield characteristics to be maintained (Fig. 5). However, including some divergence between the casings potentially provides some diffusion but within the constraints of the flowfield generated by the large downstream blockage. To demonstrate the basic strategy, the inner wall of the diffuser was placed on the streamline dividing the main compressor efflux from the inboard recirculation. The outer wall of the diffuser was placed on the outboard dividing streamline and then gradually moved outboard to provide some diffusion. In addition to increasing the amount of diffusion, this maximizes the flow turning that can be achieved for the majority of the flow, which moves radially outward. Notably, the magnitude of the high-velocity jet along the front of the flame tube is reduced. For a fixed nondimensional length of 3.0 the effect of the increasing area ratio achieved using this strategy can be observed (Fig. 6). With increasing area ratio the static pressure rise within the diffuser increases steadily up to the point of stall. As a consequence of this, the flow kinetic energy issuing from the annular diffuser is reduced, resulting in a reduction of the wall jet along the flame tube and hence reducing the loss for the flow passing around the flame tube.

The lack of relevance of conventional diffuser design charts is graphically demonstrated in Fig. 7 , which shows both the datum and integrated designs in conjunction with a line of first stall from Howard et al. [22]. Although this design line was generated for diffusers in isolation, with fully developed inlet conditions, it is commonly used in current diffuser design methodologies. The datum diffuser sits just below this line but the integrated design sits well

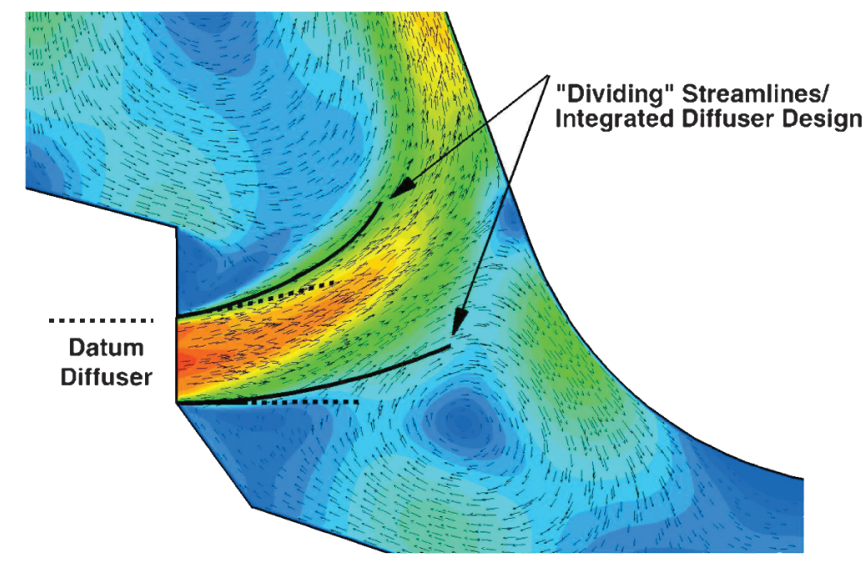

a) No diffuser (total velocity contours)
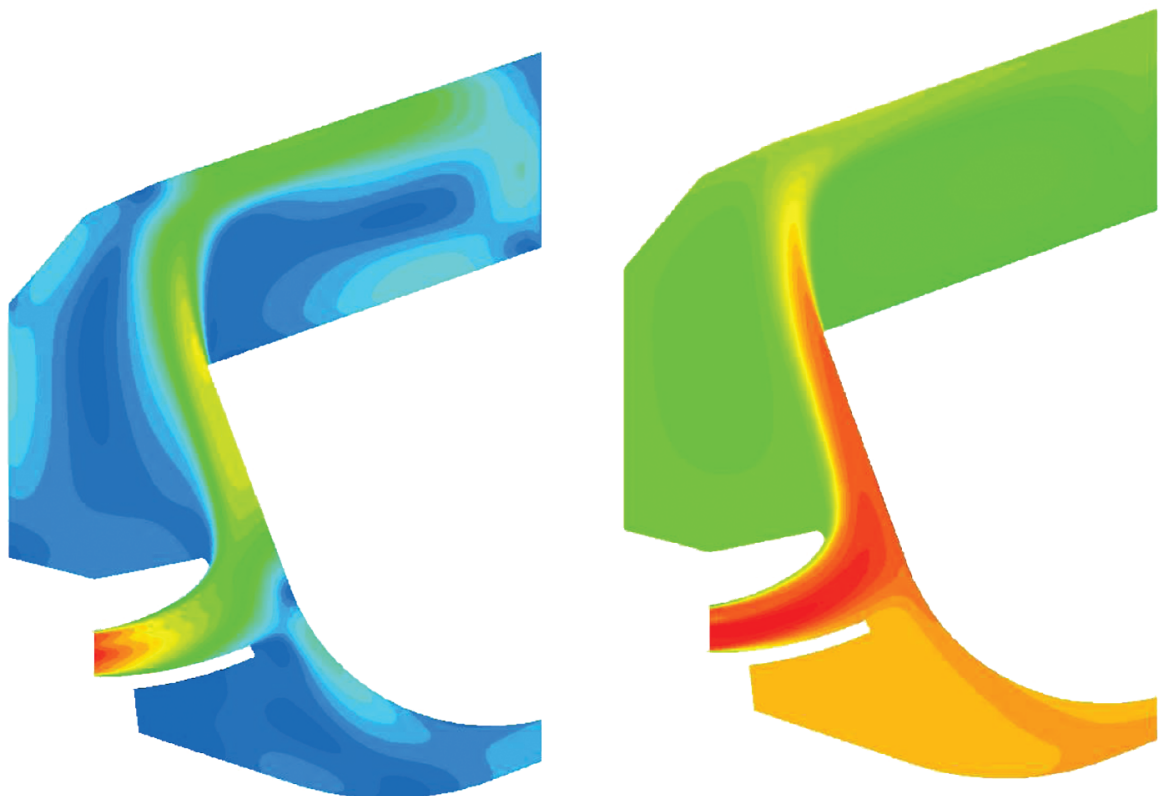

b) Integrated diffuser (total velocity and total pressure contours)

Fig. 5 Contours: integrated design. 


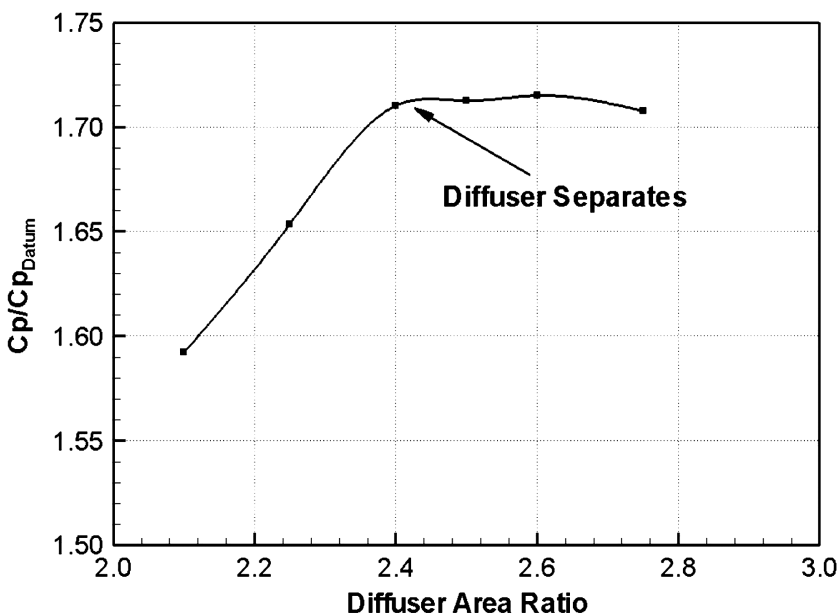

a) Diffuser static pressure rise

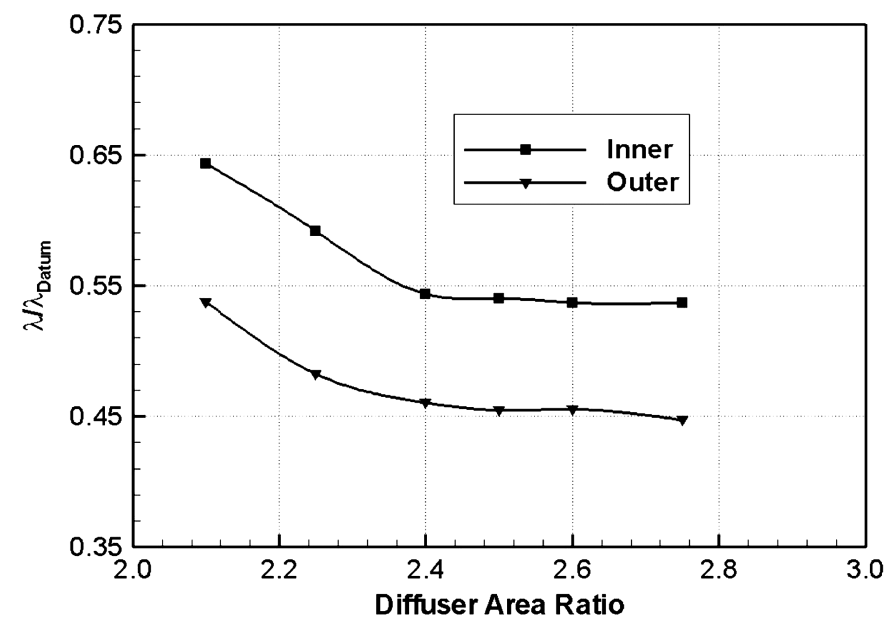

b) System total pressure loss

Fig. 6 Diffuser and system performance.

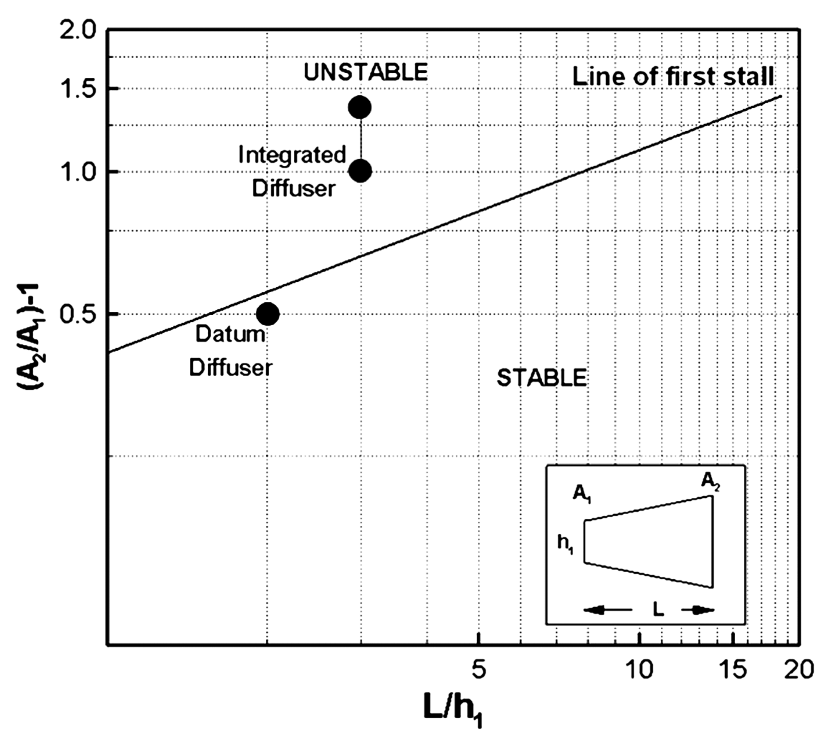

Fig. 7 Conventional diffuser loading chart.

above it in the unstable region. The design charts therefore suggest that the integrated design would clearly separate, in contrast to the evidence presented herein. This is due to the strong interaction between the diffuser and downstream geometry.

\section{Ninety-Degree Diffuser}

An alternative strategy is to turn the diffuser through $90^{\circ}$ using a circular arc (Fig. 8a). In this way, the flow does not impinge on the flame tube and the flow within the diffuser is isolated from any effects associated with the downstream flame tube. In other words, the flowfield in the diffuser is isolated from the effects of the downstream blockage. Instead, it is the diffuser itself that dominates the pressure field and the flow development within the diffuser. This also had the advantage of enabling curved diffuser loading charts (e.g., Sagi and Johnston [23]) to be used to help in the diffuser design process giving an area ratio of 1.5 for a nondimensional length of 4.0. However, it should be noted that several disadvantages arise with this concept. For example, the relatively small gap that typically exists between the OGV exit plane and the flame tube means that the rate of curvature must be high. In addition, the limited space envelope means the curvature is anticipated by the flow at the OGV trailing edge. In other words, the diffuser geometry will impact on the performance of the upstream turbomachinery blading. However, a more significant problem is that, although this concept may be suitable for the flow that passes radially outward, it severely compromises that portion of the flow that passes inboard. To illustrate this, some loss data are presented for some of the concepts investigated (Table 1), which is expressed in terms of the datum aero performance values. Note the use of a simplified model means the indicated loss values are only estimates of the likely performance. However, despite various alterations and variations based on this concept, loss values for the inboard flow were always 3 times or more greater than the datum.

\section{Ninety-Degree Bifurcated Diffuser}

A logical extension of the single-passage curved diffuser, and one that aims to reduce the inboard loss, is to split the diffuser into two passages and separately duct and diffuse the inboard flow (Fig. 8b). Here, the outer passage passed approximately $85 \%$ of the flow $\overline{a n d}$ represented a $90^{\circ}$ curved diffuser of area ratio 1.7 and nondimensional length of 4.7 . The remaining $15 \%$ of the flow passed through the inner portion, which was a conventional diffuser canted inboard at a modest $1^{\circ}$, an area ratio of 2.0, and nondimensional length of 13. Predictions indicated that the inboard loss was significantly reduced from the single-passage curved diffuser but remained higher than the datum, due to the small passage height and relatively long length. A further disadvantage of this configuration is that it will require radial struts to support the central vane. This potentially reduces the area ratio, increases the wetted area, and causes secondary flows as the casing and strut boundary layers interact.

\section{E. Full 3-D Model}

The 2-D model provided a relatively quick and easy method of exploring various concepts, and based on these results the integrated concept was thought to be the most promising. However, this simplified model does not include several features that are known to impact on diffuser performance. For example, the impact of compressor-generated inlet conditions was not included. Similarly, the interaction between the diffuser and downstream flame tube is a two-way process and requires some iteration and optimization. Changes in diffuser geometry directly change the flowfield within the diffuser and also the kinetic energy of the flow, and its direction, as it issues from the diffuser and is distributed around the flame tube. This, in turn, will affect the pressure field generated by the flame tube and its impact on the upstream diffuser. An extreme example of this is the previously illustrated $90^{\circ}$ diffuser concept, where the changes in diffuser geometry eliminated the influence of the downstream flame tube from the diffuser flowfield.

As an example of the iterative process undertaken to optimize diffuser geometry, wall shear stress values are presented for three configurations (Fig. 9). Although the prediction of imminent separation is extremely difficult using RANS-based numerical methods, it was assumed the wall shear stress values broadly indicate the relative proximity of different diffuser designs to flow separation. 


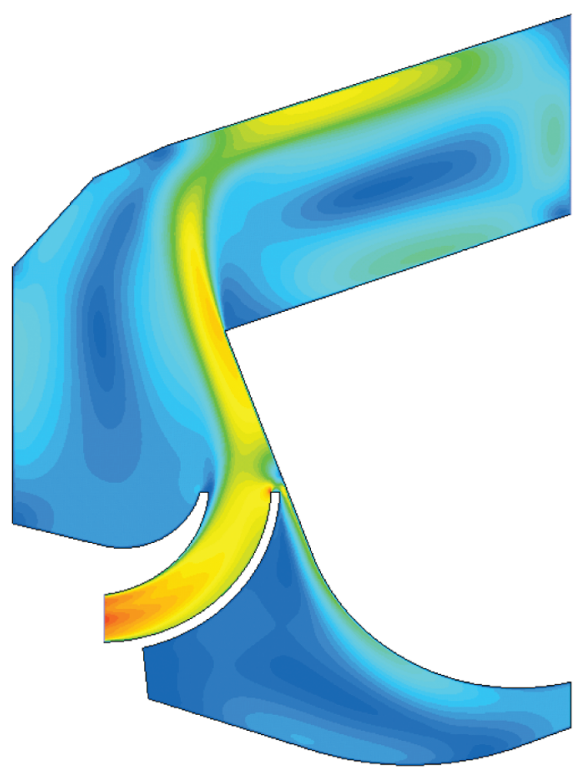

a) $90^{\circ}$ curved

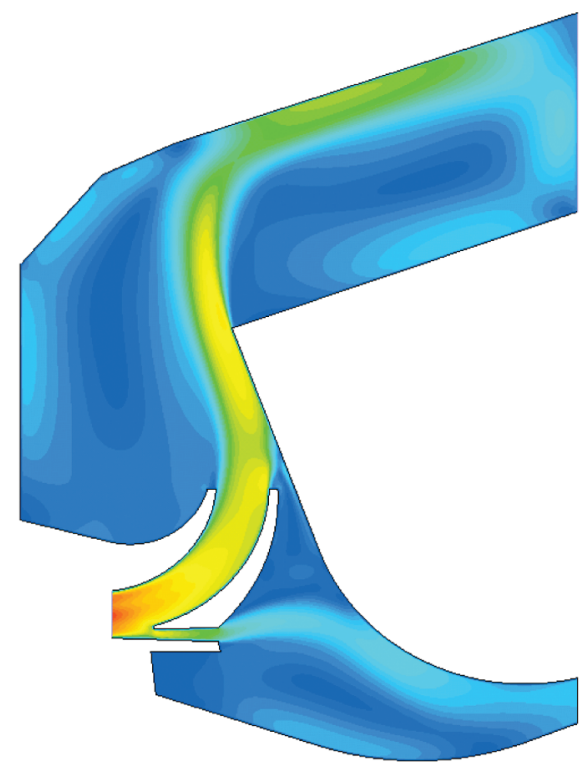

b) $90^{\circ}$ bifurcated

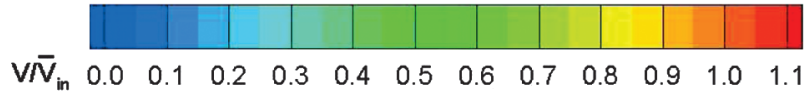

Fig. 8 Total velocity contours: alternate diffuser concepts.

Table 1 Estimated (CFD) loss data (simplified model)

\begin{tabular}{|c|c|c|c|c|c|c|c|}
\hline Diffuser & $L / h_{1}$ & $\mathrm{AR}$ & $\beta,^{\circ}$ & $C p$ (diffuser) & $\lambda$ (diffuser) & $\lambda$ (inboard) & $\lambda$ (outboard) \\
\hline Datum Aero & 2.0 & 1.5 & 12 & $C p(d)$ & $\lambda(d)$ & $\lambda$ (in) & $\lambda$ (out) \\
\hline Integrated & 3.0 & 2.25 & 26 & $1.7 \times C p(d)$ & $2.3 \times \lambda(d)$ & $0.6 \times \lambda$ (in) & $0.5 \times \lambda$ (out) \\
\hline $90^{\circ}$ Curved & 4.0 & 1.5 & 90 & $0.8 \times C p(d)$ & $1.9 \times \lambda(d)$ & $3.0 \times \lambda$ (in) & $0.5 \times \lambda$ (out) \\
\hline $90^{\circ}$ Bifurcated & 13 & 1.95 & -1 & $1.1 \times C p(d)$ & $1.1 \times \lambda(d)$ & & \\
\hline Inner/outer & 4.7 & 1.67 & 90 & $1.0 \times C p(d)$ & $1.1 \times \lambda(d)$ & $1.2 \times \lambda($ in $)$ & $0.5 \times \lambda$ (out) \\
\hline
\end{tabular}

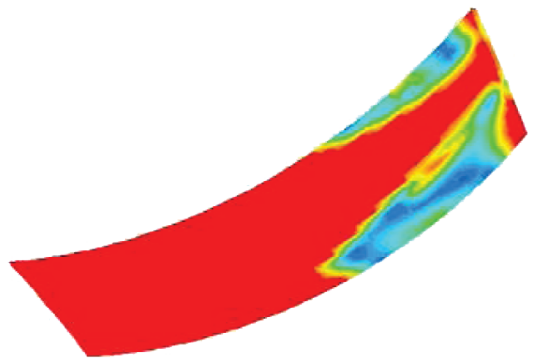

a) Area ratio 2.25

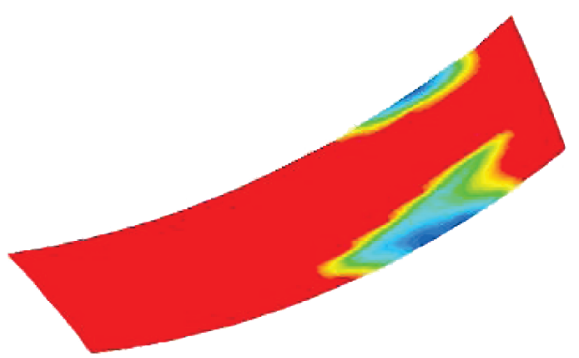

b) Area ratio 2.0

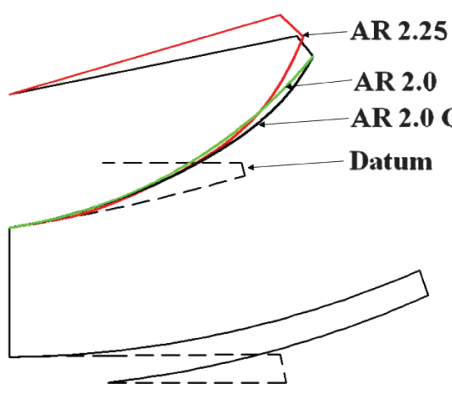

c) Wall contouring

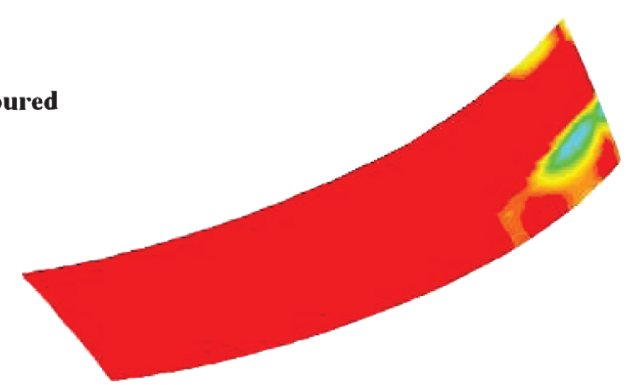

d) Area ratio 2.0 - contoured 

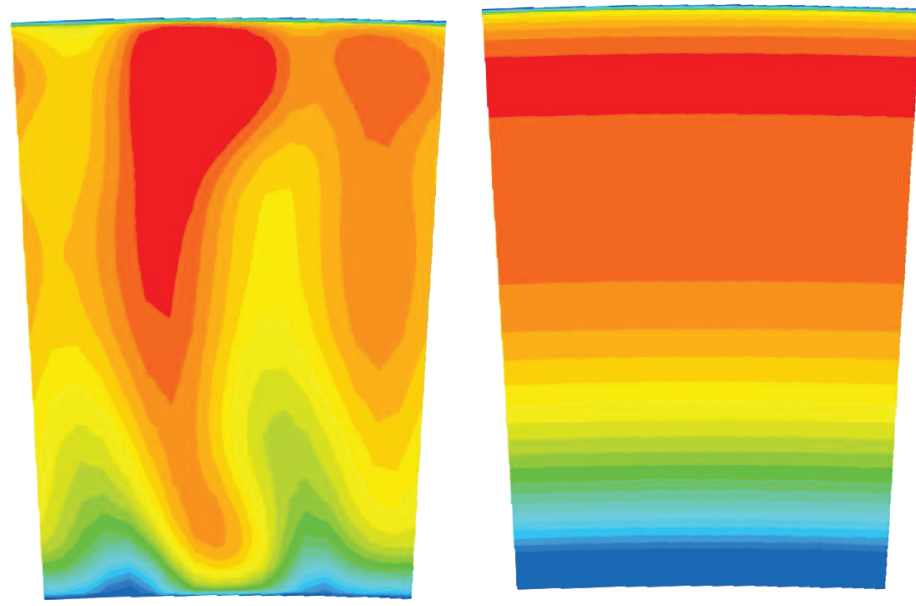

$\mathrm{U} / \overline{\mathbf{U}}$

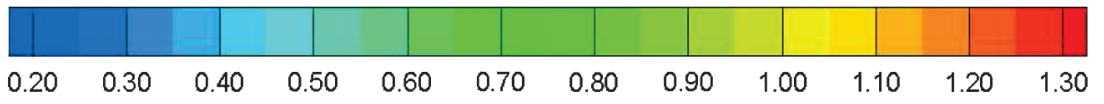

a) Normalized velocity contours at pre-diffuser exit
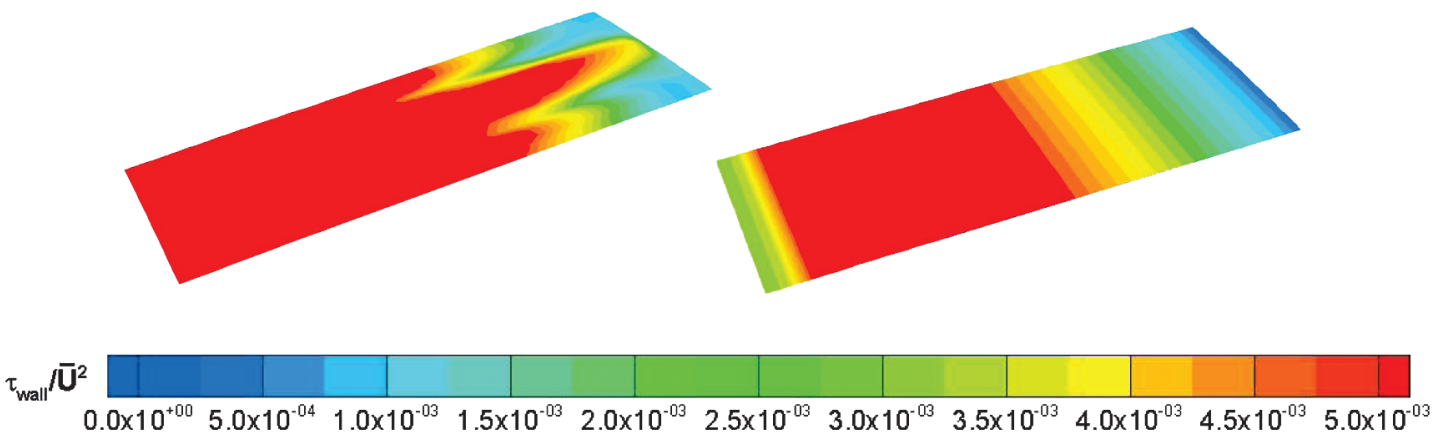

b) Diffuser inner wall shear stress

Compressor Generated Inlet

Circumferentially Averaged Inlet

Fig. 10 Effect of compressor-generated inlet conditions: datum diffuser.

Since one design objective was to maximize the outward turning of the flow, it was to be expected that the diffuser outer casing was the region where flow separation would initially occur. For the given nondimensional length, an area ratio of 2.25 generated large areas of virtually zero wall shear stress along the outer casing. Reducing the diffuser area ratio to 2.0, not surprisingly, helped to reduce this potential area of flow separation, although significant regions of low wall shear stress values were still evident. However, for the same area ratio further improvements were achieved by the use of suitable wall contouring. It could be argued that the rate of diffusion should decrease along the diffuser as the boundary layer thickens. However, in this case, the opposite strategy has proved successful. This is because of the increasing influence, with downstream location, of the pressure field associated with the flame-tube blockage. The circumferential variations in the observed values are associated with the compressor-generated inlet conditions (i.e., OGV wake). The compressor-generated inlet conditions were replaced by a circumferentially averaged profile, thus highlighting their beneficial effect. This is evident in Fig. 10, which plots velocity contours at the diffuser exit and wall shear stress for a back-to-back prediction of the datum diffuser. Without the beneficial secondary flows the inner-wall boundary layer is much thicker, the wall shear stress is noticeably reduced and the diffuser is generally closer to separation.

Overall performance of the system was mainly assessed in terms of the total pressure loss between OGV exit and various downstream locations, as summarized in Table 2 for the 3-D model. The increased diffuser area ratio and resultant re $\overline{d u c t i o n}$ in kinetic energy achieved by the integrated design suggest a reduction in the downstream losses to between 61 and $65 \%$ of those seen with the datum diffuser.

\section{Experimental Test Facility}

To validate the design concept tests were performed on the datum and integrated diffuser concepts within a fully annular atmospheric test facility (Fig. 11). A honeycomb flow straightener was located within the inlet to ensure the flow enters the rig in the axial direction. As already discussed the inlet conditions can have a crucial effect on diffuser performance so the facility used a 1.5-stage axial flow

Table 2 Estimated (CFD) performance data (3-D model)

\begin{tabular}{lcccc}
\hline \hline \multirow{2}{*}{ Station } & \multicolumn{2}{c}{ Total pressure loss coefficient $\lambda$} & \multicolumn{2}{c}{ Static pressure recovery coefficient $C p$} \\
\cline { 2 - 5 } & Datum & Integrated diffuser & Datum & Integrated diffuser \\
\hline Prediffuser exit $B$ & 0.024 & 0.035 & 0.460 & 0.675 \\
Inner annulus $C$ & 0.255 & $0.156(61 \%)$ & 0.754 & 0.842 \\
Outer annulus $E 1$ & 0.351 & $0.215(61 \%)$ & 0.198 & 0.483 \\
Outer annulus $E 2$ & 0.833 & $0.542(65 \%)$ & 0.236 & 0.499 \\
\hline \hline
\end{tabular}




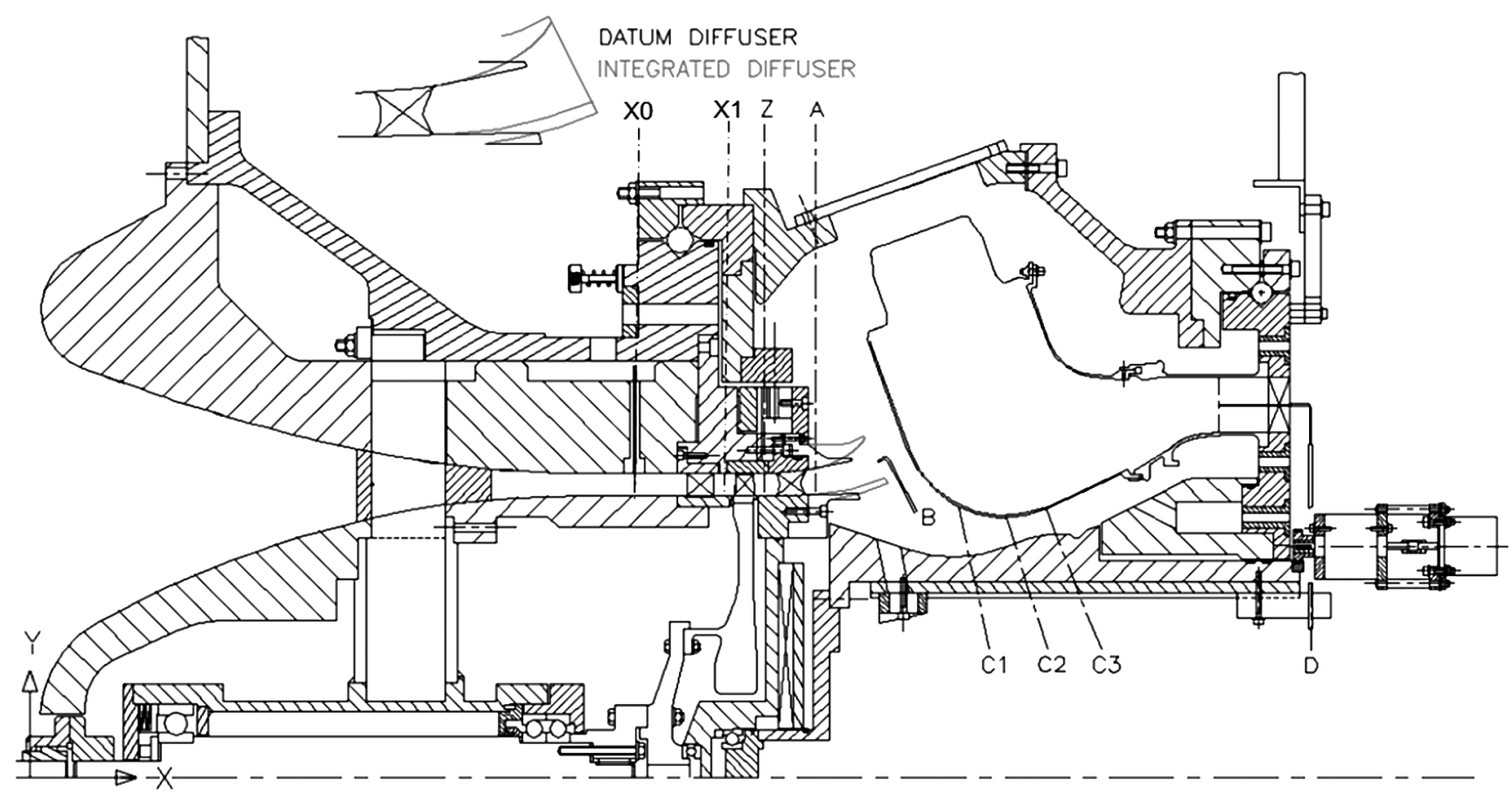

Fig. 11 Test rig schematic.

compressor upstream of the diffuser and simulated flame tube. This is thought to provide a good compromise in terms of capturing the blade wakes, secondary and rotor tip leakage flows, etc., which will have an important influence on the downstream diffuser while avoiding the costs associated with operating a multistage compressor. Design of the axial flow compressor was undertaken in conjunction with Rolls-Royce plc, with the preswirl vanes and rotor providing a suitable engine representative condition to the OGV blade row. The blade loadings and other aerodynamic loading parameters are broadly representative of design practice relating to the back of a high-pressure compressor. The operating speed of the compressor was such as to maintain a Reynolds number based on the OGV chord of approximately $2 \times 10^{5}$. As described by Cumpsty [24], this is sufficient to avoid any transitional effects. The compressor nondimensional speed $\left(N \pi D / \sqrt{ }\left(\gamma R T o_{1}\right)\right)$ and flow coefficient $\left(\mathrm{Va} / \mathrm{U}_{\text {blade }}\right)$ were maintained to within $\pm 0.08 \%$ and $\pm 0.18 \%$, respectively, of their prescribed values. The simulated flame tube incorporated fuel injectors that were thought to broadly reflect the design practice for a low-emissions-type combustion system. Flow exits the combustion system via the flame tube or the simulated coolant bleeds (NGV inner and outer platforms and turbine disk flows).

In general aerodynamic performance was assessed using suitably calibrated miniature five-hole probes $(\phi=1.76 \mathrm{~mm})$ as described by Wray and Carrotte [25] and employed in a nonnulled mode to determine the local flow vector and total and static pressures. As indicated in Fig. 11, area traverses could be conducted at rig inlet $X 0$, rotor inlet $X 1$, rotor exit $Z, \mathrm{OGV}$ exit $A$, prediffuser exit $B$, and in three locations within the inner annulus $(C 1-C 3)$. Probes were traversed in the radial direction using a stepper motor powered linear guide with positional accuracy of better than $\pm 0.1 \mathrm{~mm}$. Circumferential probe movement (over a given repeatable sector) was achieved by rotating the inner and outer casings about the rig centerline using a high-powered stepper or dc servomotor. It is estimated that a probe could be positioned to within $\pm 0.05^{\circ}$ of the desired location. All data were corrected to International Standard Atmosphere standard day conditions.

Overall aerodynamic performance was quantified in terms of the total pressure loss and static pressure recovery as defined previously. The mass flow balance on area traverse planes was within $\pm 1 \%$ of the rig mass flow entering the test facility measured via a five-hole probe traverse at plane $\mathrm{X} 1$. The mass-weighted total pressures were repeatable to within $\pm 1 \mathrm{~mm} \mathrm{H}_{2} \mathrm{O}$, which amounts to less than $\pm 0.5 \%$ of the dynamic pressure at OGV exit. Thus, the repeatability of the derived total pressure loss and static pressure rise coefficients was better than \pm 0.005 of the values presented.

\section{Results and Discussion}

\section{A. OGV Exit/Diffuser Inlet}

Measurements with both the datum and integrated diffusers were obtained across a circumferential sector corresponding to two OGV blade spaces. As expected the nondimensional total pressure contours (Fig. 12) indicate the presence of well-defined blade wakes, loss cores, and other features that are generated by the upstream compressor OGV row. The contours also indicate that, within experimental error, the flowfields entering each diffuser geometry are virtually the same. This is further indicated by the circumferentially averaged pressure profiles (total and static) and yaw-angle profiles at this location (Fig. 13). As expected, there was a small amount of residual swirl entering the diffusers, and a thicker boundary layer was present along the outer casing, with the profile being slightly hubbiased. What should also be noted, though, is similarity of the static profiles for the different geometries. In other words, the design intent of maintaining the same static pressure distribution at the trailing edge of the OGV blade row, despite changes in the diffuser geometry, was achieved. Thus, within an engine the impact of changes in diffuser geometry on the upstream turbomachinery blading and its performance would be minimized.

\section{B. Prediffuser Exit}

In contrast to $\mathrm{OGV}$, exit differences were apparent in the axial velocity contours (Fig. 14) and circumferentially averaged profiles for the different diffusers (Fig. 15). For the datum geometry a radial static pressure profile is evident due to the presence of the downstream flame tube, which tries to turn the flow radially outward. Relative to OGV exit the axial velocity contours indicate mixing out of the compressor wakes and a more tip-biased profile. This is caused by the outboard movement of fluid, within the diffuser, which is due to the influence of the radial pressure gradient associated with the downstream flame-tube blockage. However, this movement is restricted by the outer casing of the datum diffuser and this is further suggested by the pitch-angle profile, which reaches a maximum of $20^{\circ}$. In contrast, the integrated diffuser tries to accommodate the impact of the downstream blockage on the flowfield as it tries to 

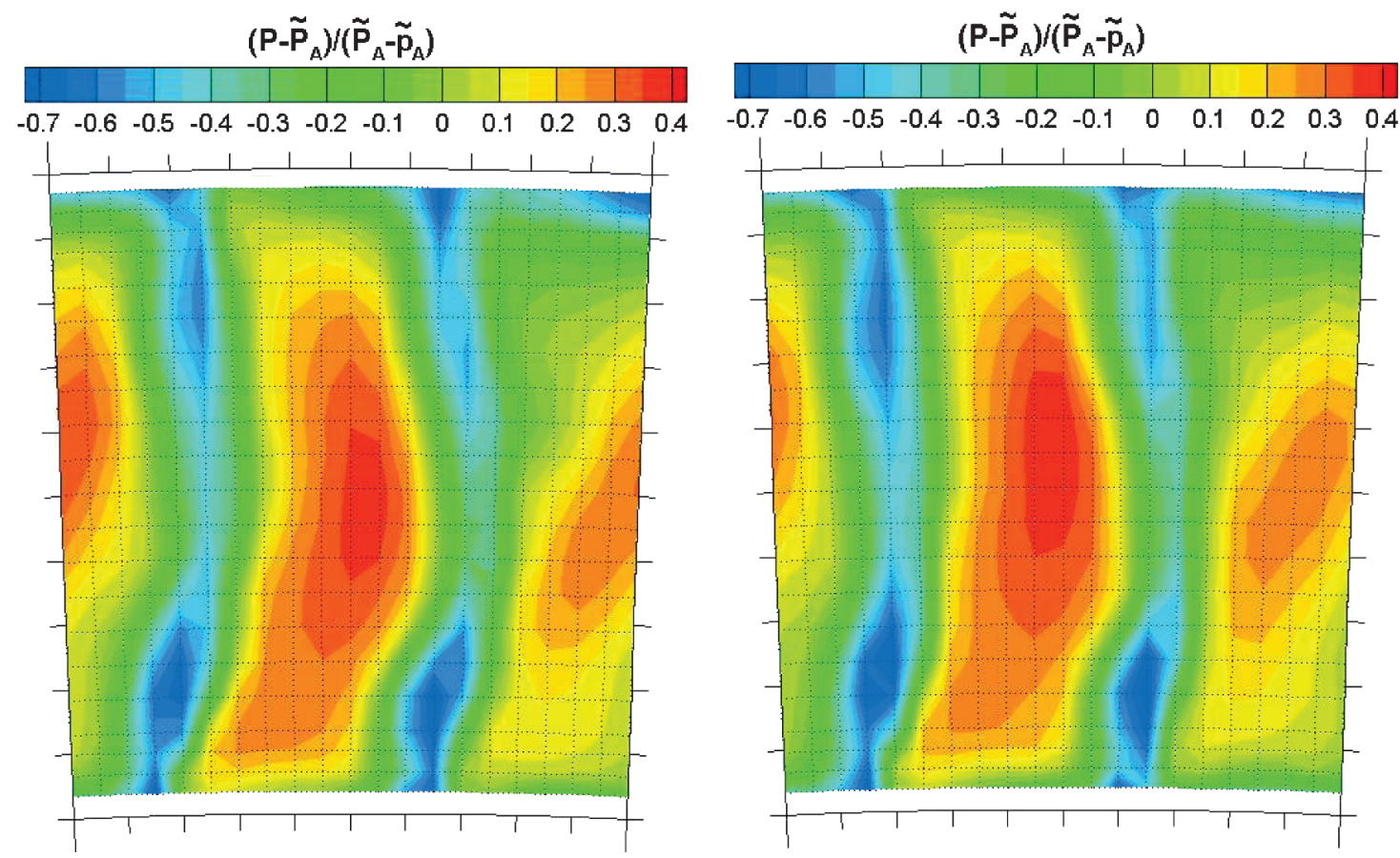

a) Datum diffuser

b) Integrated diffuser

Fig. 12 Normalized total pressure contours at ogv exit $(A)$.

diffuse the flow. Hence, a radial pressure gradient is still evident at prediffuser exit, but the geometry allows the flow to turn while also diffusing the flow. In addition, the passage area indicated by the axial velocity contours is a graphic illustration of the increased diffuser area ratio associated with this geometry. The increased pressure rise will cause a thickening of the boundary layer, and this is greatest along the outer casing as it tries to help turn the flow radially outward. Comparison with the datum configuration indicates velocity contours in this outer-casing region are now comparable with those observed close to the inner casing for the datum configuration. Evidence of the greater flow turning now being achieved is reflected in the circumferentially averaged pitch-angle distribution, which

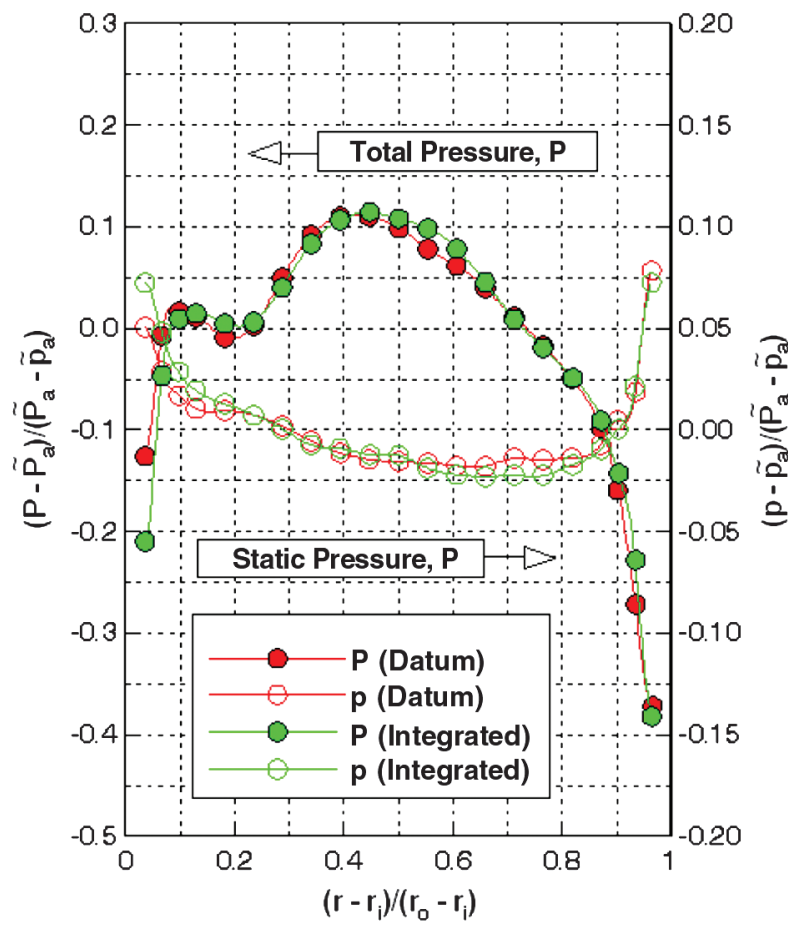

now varies from $20-65^{\circ}$ (compared with the maximum value of $20^{\circ}$ for the datum). Note that the slight downturn in pitch angle (Fig. 15) near the outer wall is due to a wall interference effect on the response of the probe; the prediffuser exit traverse is just upstream of the prediffuser exit plane.

In terms of diffuser performance the loss coefficient of the integrated design has almost doubled relative to the datum (from 0.044 to 0.086 ). However, this has been accompanied by a $50 \%$ increase in the static pressure recovery (from 0.403 to 0.605 ). Changes in the kinetic energy flux coefficient $\alpha$ between diffuser inlet and exit are comparable for both configurations. These values are mainly dominated by the circumferential nonuniformities

Fig. 13 Circumferentially averaged pressure and swirl profiles at ogv exit $(A)$.

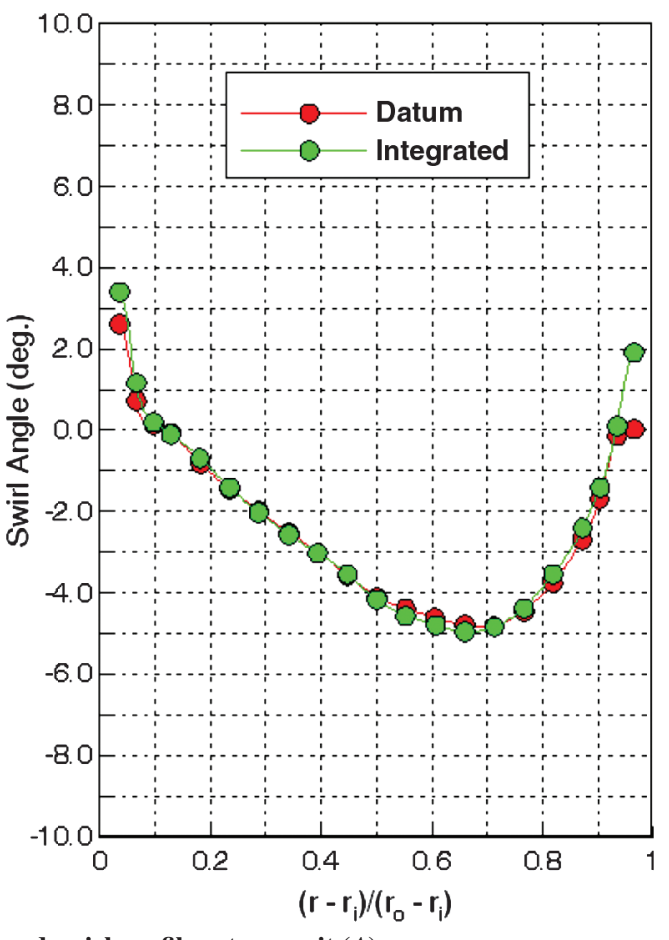




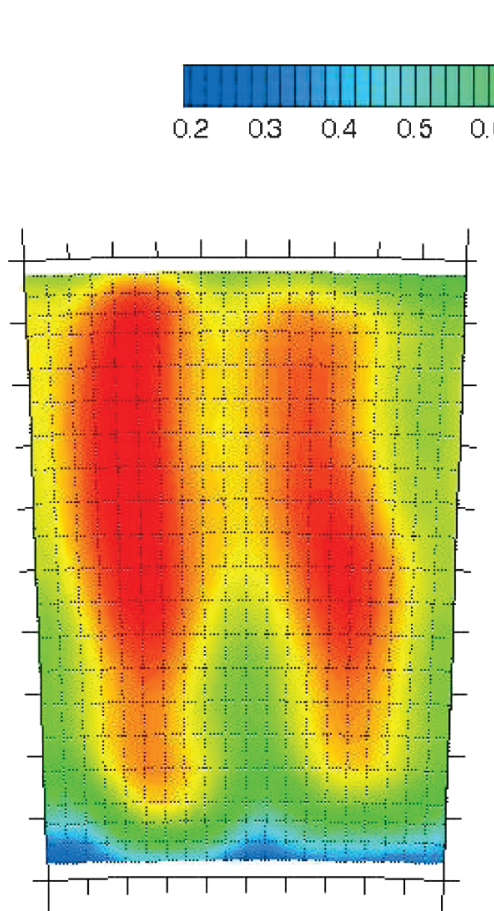

a) Datum diffuser

\section{$\mathbf{U} / \overline{\mathbf{U}}$}

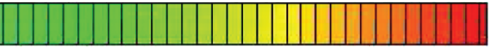

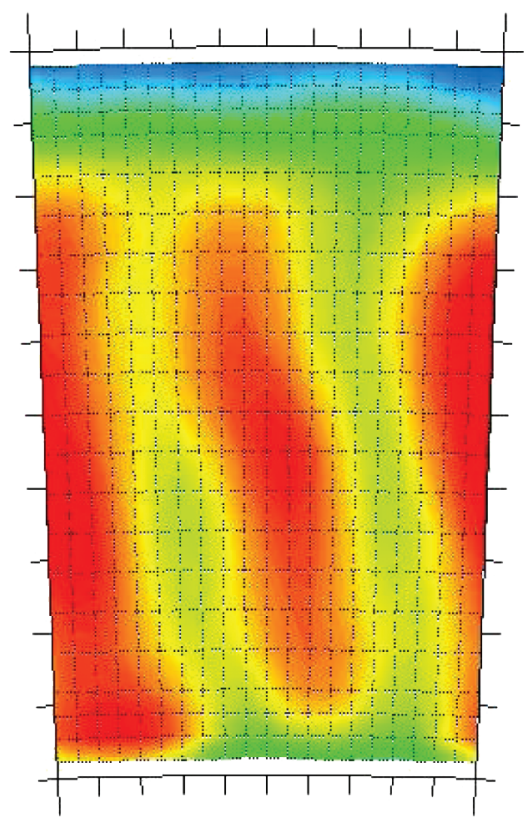

b) Integrated diffuser

Fig. 14 Normalized axial velocity contours at the diffuser exit $(B)$.

associated with the OGV blade wakes and suggest similar mixing out of the wakes within each configuration. Hence, the increased static pressure rise of the integrated design is mainly a function of the larger diffuser area ratio. An estimate of diffuser efficiency can be obtained if it is assumed the measured total pressure loss in each configuration had been converted to a static pressure rise. This suggests comparable diffuser efficiencies of order $90 \%$ (datum) and $87 \%$ (integrated design). However, the most important point to note from the diffuser performance data is the significant reduction in the flow kinetic energy issuing from the integrated diffuser. Thus, although the loss within the integrated diffuser has increased, the loss-generating mechanisms downstream of the diffuser within the combustion system will be significantly reduced.

\section{Overall Performance}

The overall performance of the system is mainly assessed in terms of the total pressure loss between OGV exit and the various downstream locations through which the flow leaves the combustion system. For turbine-cooling this includes the flows being supplied to the turbine disk and the NGV inner and outer platforms. In addition, although it is difficult to accurately measure the total pressure of the flow being presented to the fuel injectors, a detailed traverse enables the total pressure at combustor exit to be obtained. These data are summarized in Table 3 . Generally speaking, the reduction in kinetic energy achieved by the integrated diffuser has reduced the downstream losses by between 66 and $79 \%$. This is a significant performance benefit for the combustion system, and it has been
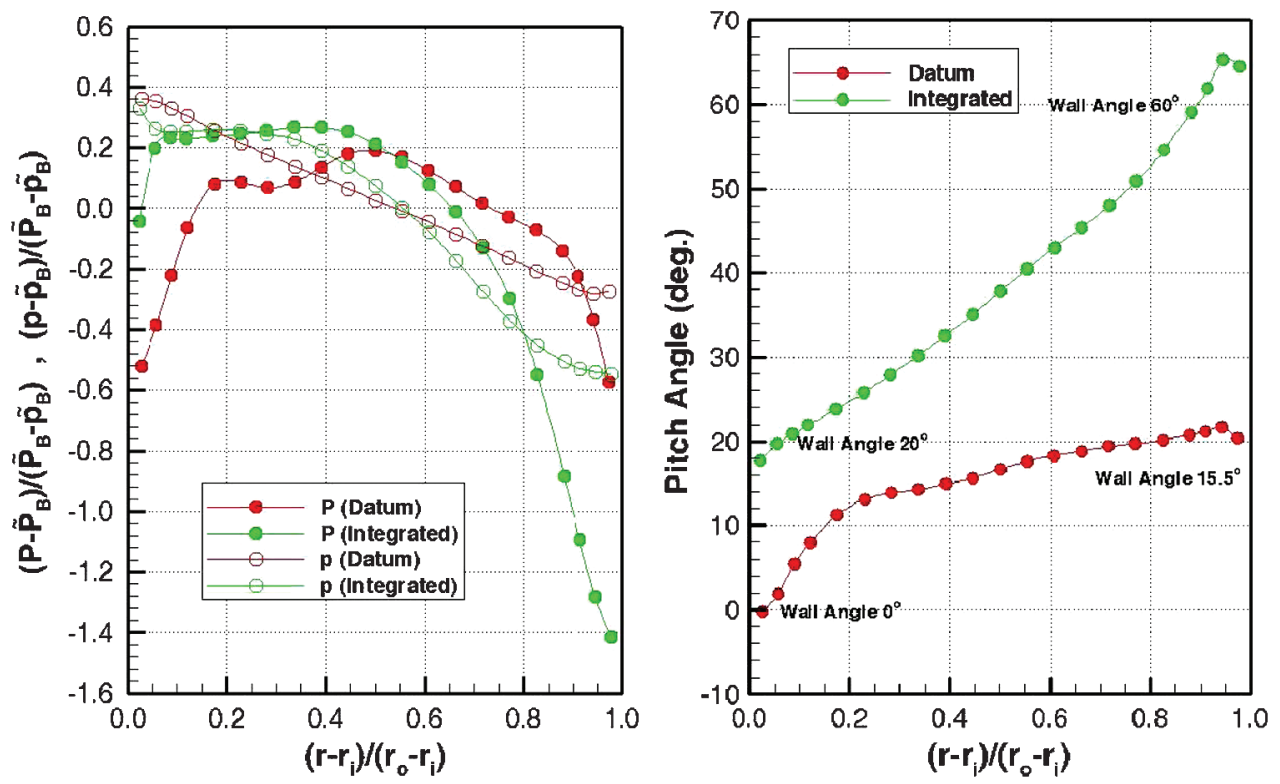

Fig. 15 Circumferentially averaged pressure and pitch profiles at the diffuser exit $(B)$. 
Table 3 Experimentally measured performance data

\begin{tabular}{lcccc}
\hline \hline \multirow{2}{*}{ Station } & \multicolumn{2}{c}{ Total pressure loss coefficient $\lambda$} & \multicolumn{2}{c}{ Static pressure recovery coefficient $C p$} \\
\cline { 2 - 5 } & Datum & Integrated diffuser & Datum & Integrated diffuser \\
\hline Prediffuser exit $B$ & 0.044 & 0.086 & 0.403 & 0.577 \\
Combustor exit $D$ & 1.259 & $0.995(79 \%)$ & - & - \\
Inner annulus $C 2$ & 0.291 & $0.195(67 \%)$ & 0.652 & - \\
Turbine disk coolant & 0.390 & $0.264(68 \%)$ & - & - \\
NGV inner platform & 0.312 & $0.210(67 \%)$ & - & - \\
NGV outer platform & 0.706 & $0.465(66 \%)$ & - & - \\
\hline \hline
\end{tabular}

Table 4 Effect of varying dump gap and integrated diffuser length

\begin{tabular}{lcccccc}
\hline \hline Dump gap & $L / h_{\mathbf{1}}$ & $\mathrm{AR}$ & $C p$ (diffuser) & $\lambda$ (diffuser) & $\lambda$ (inboard) & $\lambda$ (outboard) \\
\hline Original & 3.0 & 2.0 & $C p(d)$ & $\lambda(d)$ & $\lambda$ (in) & $\lambda$ (out) \\
$-5 \%$ & 3.0 & 2.0 & $1.00 \times C p(d)$ & $1.00 \times \lambda(d)$ & $1.01 \times \lambda($ in) & $1.04 \times \lambda$ (out) \\
$-15 \%$ & 3.0 & 2.0 & $1.00 \times C p(d)$ & $1.01 \times \lambda(d)$ & $1.04 \times \lambda($ (in) & $1.13 \times \lambda$ (out) \\
$-30 \%$ & 3.0 & 2.0 & $0.98 \times C p(d)$ & $1.03 \times \lambda(d)$ & $1.11 \times \lambda($ in) & $1.38 \times \lambda$ (out) \\
Original $(-15 \%)$ & 2.75 & 1.85 & $0.95 \times C p(d)$ & $0.96 \times \lambda(d)$ & $1.04 \times \lambda($ in) & $1.10 \times \lambda$ (out) \\
Original $(-30 \%)$ & 2.6 & 1.7 & $0.90 \times C p(d)$ & $0.89 \times \lambda(d)$ & $1.10 \times \lambda($ (in) & $1.25 \times \lambda$ (out) \\
\hline \hline
\end{tabular}

achieved by accommodating the interaction of the diffuser with the downstream geometry in the design process, as opposed to using conventional diffuser design charts, which are of limited use. Furthermore, in aero-derivative engines it also demonstrates the performance benefits of changing the diffuser geometry in addition to, more commonly, just the flame tube and combustor casings.

\section{Modified Diffuser Designs}

The annular diffuser geometry was derived by consideration of the significant interaction that occurs with the downstream flame tube, and the measured performance data have indicated the success of this integrated design approach. However, in a practical engineering environment, effects such as manufacturing tolerances and thermal distortions mean that there will inevitably be some variation in the relative position of the diffuser and flame tube. This can potentially change the interaction between these components and, if the system is too sensitive, lead to significant variations in system performance. Having validated the numerical predictions with the experimental data, this effect was investigated using the simple 2-D model previously described.

To investigate the system sensitivity, the dump gap (i.e., the distance between the diffuser and flame tube) was reduced by $5 \%$. This is thought to be a reasonable reflection of the change that could be encountered due to component tolerances, thermal effects, etc. Relative to the original integrated geometry (Table 4) it can be seen that the diffuser loss is unaffected, whereas relatively small loss increases are observed for the flow passing to the outboard (4\%) and inboard (1\%) exit planes at the rear of the combustion system. However, to indicate the importance of the diffuser/flame-tube interaction, additional predictions were done with the dump gap reduced by 10 and $15 \%$. For these configurations the interaction between the diffuser and flame tube is significantly modified. Not only does the diffuser performance start to be adversely affected, but significant loss changes are observed to the outboard and inboard exit planes. This is because the reduced dump gap causes an increase in the turning loss and an increase in the velocity along the front face of the flame tube (Fig. 16). As a consequence, the outer-passage loss

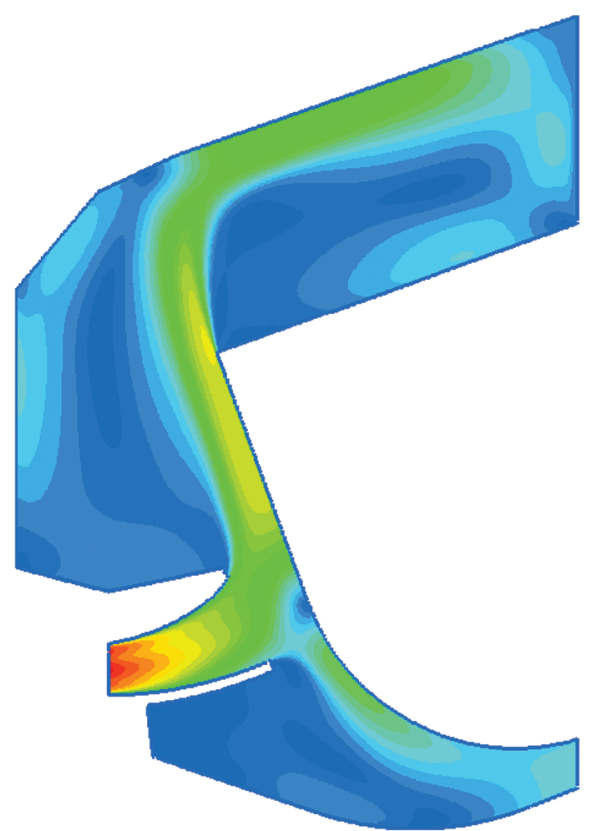

a) $15 \%$ reduction in dump gap

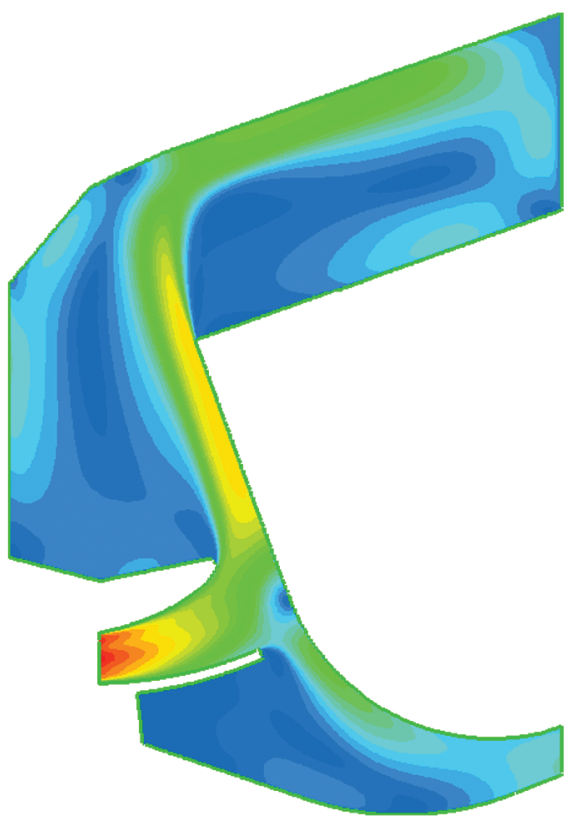

b) $30 \%$ reduction in dump gap

Fig. 16 Total velocity contours; dump gap reduced by upstream movement of flame tube. 
increases significantly by 13 and $38 \%$, respectively, as the dump gap is reduced by 10 and $15 \%$, and increased losses are also observed for the inboard flow. Additional calculations were also undertaken with the flame tube move forward by 15 and $30 \%$ and with the diffuser also cropped back a corresponding amount to return the dump gap to the original size. In this case, shortening of the diffuser reduces its area ratio, resulting in a lower static pressure recovery. Furthermore, the diffuser efflux now has significantly higher kinetic energy, and the resultant downstream losses increase.

These additional calculations illustrate how the final integrated diffuser design is closely coupled to the pressure field generated by the flame tube and for an optimized design modifications to the latter necessitate modifications to the former. However, the system is tolerant to small geometrical changes as might occur within a practical engineering environment due to thermal effects, component tolerances, etc.

\section{Conclusions}

An annular diffuser has been designed and evaluated for use in the combustion system of an aero-derivative low-emission land-based gas turbine. The design methodology considered interaction with both the upstream and downstream components and accounts for the effects of compressor-generated inlet conditions and the presence of a complex combustion system. The latter was characterized by its close proximity, a high degree of blockage, and a flow distribution where immediately downstream of the diffuser approximately $85 \%$ of the flow moves radially outboard. Numerical methods of varying complexity were used to develop several diffuser design concepts that demonstrated 1) the interaction between the diffuser and downstream geometry and 2) how this interaction varies with changes in diffuser geometry. Through careful consideration of the flowfield an integrated concept was developed, using an iterative process, to enable the interaction between the diffuser and flame tube to be accommodated. The concept was experimentally evaluated on a lowspeed facility that simulated the combustion system while also providing compressor-generated inlet conditions. A conventionally designed diffuser system was also evaluated and, with reference to this datum, it was shown that the combustion system total pressure losses were reduced by between 20 and $35 \%$.

\section{References}

[1] Stevens, S. J., Nayak, U. S. L., Preston, J. F., and Scrivener, C. T. J., "Influence of Compressor Exit Conditions on Diffuser Performance," Journal of Aircraft, Vol. 15, No. 8, 1978, pp. 482-488. doi: $10.2514 / 3.58394$

[2] Stevens, S. J., and Williams, G. J., "The Influence of Inlet Conditions on the Performance of Two Annular Diffusers," Journal of Fluids Engineering, Vol. 102, No. 3, 1980, pp. 357-363. doi:10.1115/1.3240694

[3] Stevens, S. J., Harasgama, S. P., and Wray, A. P., "The Influence of Blade Wakes on Combustor Shortened Pre-diffusers," Journal of Aircraft, Vol. 21, 1984, pp. 641-648. doi: $10.2514 / 3.45009$

[4] Klein, A., "The Relation Between Losses and Entry Flow Conditions in Short Dump Diffusers for Combustors," Zeitschrift für Flugwissenschaften und Weltraumforschung, Vol. 12, 1988, pp. 286-292.

[5] Klein, A., "Characteristics of Combustor Diffusers," Progress in Aerospace Sciences, Vol. 31, No. 3, 1995, pp. 171-271. doi:10.1016/0376-0421(95)00006-K

[6] Zierer, T., "Experimental Investigation of the Flow in Diffusers Behind an Axial Flow Compressor," ASME International, Paper 93-GT-347, 1993.

[7] Barker, A. G., and Carrotte, J. F., 2001, "The Influence of Compressor Exit Conditions on Combustor Annular Diffusers-Part I: Diffuser Performance," Journal of Propulsion and Power, Vol. 17, No. 3, 2001, pp. 678-686. doi: $10.2514 / 2.5795$

[8] Barker, A. G., and Carrotte, J. F., "The Influence of Compressor Exit Conditions on Combustor Annular Diffusers-Part II: Flow Redistribution Within the Diffuser," Journal of Propulsion and Power, Vol. 17, No. 3, 2001, pp. 687-694.

doi:10.2514/2.5796

[9] Walker, A. D., Carrotte, J. F., and McGuirk, J. J., "Enhanced External Aerodynamic Performance of a Generic Combustor Using and Integrated OGV/Pre-Diffuser Design Technique", Journal of Engineering for Gas Turbines and Power, Vol. 129, No. 1, 2007, pp. $80-87$.

doi: $10.1115 / 1.2364008$

[10] Japikse, J., Turbo-Machinery Diffuser Design Technology, Concepts ETI, Norwich, VT, 1984.

[11] Jayatunga, C., "Experimental and Computational Studies of Exhaust Volutes Dynamics," Ph.D. Thesis, Department of Aeronautical and Automotive Engineering, Loughborough University, Loughborough, England, U.K., 2005.

[12] Fishenden, C. R., and Stevens, S. J., "Performance of Annular Combustor-Dump Diffusers", Journal of Aircraft, Vol. 14, No. 1, 1977, pp. 60-67. doi: $10.2514 / 3.58749$

[13] Bailey, D., Carrotte, J. F., and Frodsham, C. W., "Detailed Measurements on a Modern Combustor Dump Diffuser System," Journal of Engineering for Gas Turbines and Power, Vol. 117, No. 4, 1995, pp. 678-685. doi:10.1115/1.2815453

[14] Walker, A. D., Carrotte, J. F., and McGuirk, J. J., "Compressor/Diffuser/ Combustor Aerodynamic Interactions in Lean Module Combustors", Journal of Engineering for Gas Turbines and Power, Vol. 130, No. 1, 2008, pp. 011504. doi:10.1115/1.2747646

[15] Walker, A. D., Carrotte, J. F., and McGuirk, J. J., "The Influence of Dump Gap on External Combustor Aerodynamics at High Fuel Injector Flow Rates," Journal of Engineering for Gas Turbines and Power, Vol. 131, No. 3, 2009, Paper 031506. doi:10.1115/1.3028230

[16] Versteeg, H. K., and Malalasekera, W., Introduction to Computational Fluid Dynamics: The Finite Volume Method, Harlow-Longman, 1995.

[17] Craft, T. M., and Launder, B. E., "Computational Impinging of Flows Using Second Moment Closures," Eighth Symposium on Turbulent Shear Flows, Technical University of Munich, Paper 8-5, 1991.

[18] Bradshaw, P., "Effects of Streamline Curvature on Turbulent Flow," AGARDograph, AG 169, 1973.

[19] Little, A. R., Denman, P. A., and Manners, A. P., "Prediction and Measurement of the Total Pressure Loss in an Engine Representative Diffuser System," Journal of Turbomachinery, Vol. 119, No. 2, 1997, pp. 390-396. doi:10.1115/1.2841123

[20] Britchford, K. M., Manners, A. P., McGuirk, J. J., and Stevens, S. J., "Measurements and Prediction of Flow in Annular S-Shaped Ducts," Second International Symposium on Engineering Turbulence Modeling and Measurements, Florence, Italy, 1993.

[21] Walker, A. D., "Experimental and Computational Study of Hybrid Diffusers for Gas Turbine Combustors," Ph.D. Thesis, Department of Aeronautical and Automotive Engineering, Loughborough University, Loughborough, England, U.K., 2002.

[22] Howard, J. H. G., Henseler, H. J., and Thornton-Trump, A. B., "Performance and Flow Regimes for Annular Diffusers," ASME International, Paper 67-WA/FE-21, 1967.

[23] Sagi. C. J., and Johnston, J. P., "The Design and Performance of TwoDimensional, Curved Diffusers", Journal of Basic Engineering, Vol. 89, 1967, pp. 715-731.

[24] Cumpsty, N. A., Compressor Aerodynamics, Longman Scientific and Technical, Harlow, England, 1989.

[25] Wray, A. P., and Carrotte, J. F., "The Development of a Large Annular Facility for Testing Gas Turbine Combustor Diffuser Systems," AIAA Paper 93-2546, 1993. 